\title{
A Forecast of Effective Energy Efficient Policies for the Building Sector in Shanghai through 2050
}

\author{
Rui Xing ${ }^{1, *}$, Toshiharu Ikaga ${ }^{1}$, Manfred Strubegger ${ }^{2}$ \\ ${ }^{1}$ Keio University, Yokohama, Japan \\ ${ }^{2}$ International Institute for Applied Systems Analysis (IIASA), Vienna, Austria \\ *Corresponding author. Tel.: +81 45566 1808, Fax: +81 45566 1770, E-mail: xingrui@a6.keio.jp
}

\begin{abstract}
Currently in China, the energy consumption of buildings is increasing rapidly. In this study, we used a macro-model to forecast the energy consumption of buildings in Shanghai through 2050. Total energy consumption from 2000 to 2050 and the potential energy savings were projected for both the residential and commercial sectors. For urban residential buildings, we developed a forecast model for 2050 to estimate the potential energy savings of residential measures. Compared to the business-as-usual (BaU) scenario, implementation of residential measures achieved a $24 \%$ reduction in energy consumption. The reduction rate rose to $65 \%$ by combining the implementation of residential and electrical measures. For commercial buildings, we first used official statistical data to determine the energy intensities of air conditioning, lighting, computing, and other thermal uses for the base year 2000. Then, estimates of the labor force, GDP, and floor area were predicted through 2050 according to past growth patterns and the literature. Likewise, estimates for energy intensities through 2050 were projected. Energy-saving scenarios also were integrated into the commercial model. Compared to $\mathrm{BaU}$ scenario, implementation of commercial measures achieved an $80 \%$ reduction in energy consumption. The reduction rate increased to $99 \%$ by combining commercial and electrical measures.
\end{abstract}

Keywords: Shanghai, Energy consumption, Buildings, Forecasting

\section{Introduction}

At the UN Climate Conference in Copenhagen in 2009, the European Union formulated the goals that temperature increase by no more than $2{ }^{\circ} \mathrm{C}$, that global emissions peak no later than 2020 , and that by 2050 global emissions be reduced to a level that is at least $50 \%$ below the figure for 1990. These goals require action by both industrialized nations and developing countries (Gaines and Jager, 2009). In the Copenhagen Accord, the Chinese government announced mitigation action to reduce $\mathrm{CO}_{2}$ emissions per unit of GDP by 2020 to $40-45 \%$ of the 2005 level. This target was reaffirmed at the 2010 UN Climate Conference in Cancun. However, the most efficient way to achieve this reduction goal remains an unsolved problem.

In recent years, the economy of China has developed rapidly, which encourages demand for higher living standards and energy consumption. In this paper, we focus specifically on urban buildings in Shanghai, which is one of the biggest cities in China and has the highest GDP among all Chinese cities. First, we investigated the environmental performance of both residential and commercial buildings in Shanghai. Then, to quantify their sustainability, we developed macro-models to forecast $\mathrm{CO}_{2}$ emissions for both residential and commercial buildings. The forecasts include global warming countermeasures and are intended to support decision making for determining reasonable $\mathrm{CO}_{2}$ emission reductions.

\section{Methodology}

\subsection{Residential Projections}

\subsubsection{Summary of the macro-model}

The macro-model used for the residential sector has been modified from the "Estimation Macro-model for Residential Energy Consumption" (Ikaga, 2004). The flow chart in Fig. 1 


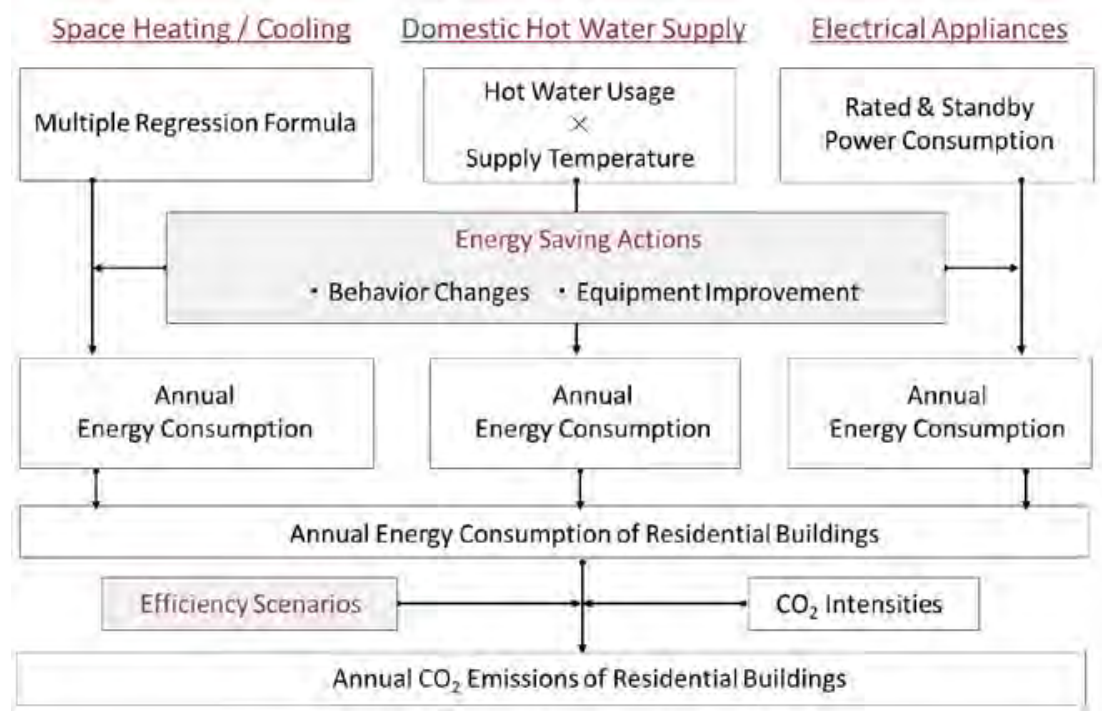

Fig. 1. Flow chart of the residential sector macro-model.

provides an overview of the model. It is a simulation model that estimates changes in energy consumption on the basis of family type, application, and energy source for each year. Estimation methods are described below.

Space heating/cooling: Annual load per household was calculated using a multiple regression equation for heating and cooling load. The annual total load of each city was computed multiplying the number of households of each household type by the energy use for the respective household type and taking the summation.

Domestic hot water supply: The total load of each city was calculated using the frequency of hot water use, the number of households and the average temperature of tap water for each month. Furthermore, energy consumption was calculated using the ratio of owned equipment and the average coefficient of performance (COP) by fuel type.

Other electrical appliances: Energy consumption was calculated as the product of the cumulative energy consumption per household per day and family type, the number of households, and the number of days in each month.

Total $\mathrm{CO}_{2}$ emissions: By totaling the results of the three functions calculated above and multiplying by the $\mathrm{CO}_{2}$ intensity of electricity for each energy source, we calculated the annual total $\mathrm{CO}_{2}$ emissions.

\subsubsection{Model parameters}

The present model is based on a macro-model that was used to calculate the national residential $\mathrm{CO}_{2}$ emissions in Japan. For the case of Shanghai, we switched the entire calculation database. The parameters that were set include the number and size of households, average gross floor area, and several pieces of household data. The parameters come either from official statistics or are based on the Chinese government development plan.

There were several parameters for which we could not find a source. To set these parameters we referred to data for the Japanese city of Fukuoka in place of Shanghai, as the two cities have similar latitudes and climates. 


\subsubsection{Scenarios}

In this study, two scenarios are examined: one for residential measures and another for electrical measures. In the residential scenario, we recommend behavioral changes and equipment improvements as global warming countermeasures, having taken into account the social conditions and citizens' lifestyles in China. All the measures are listed in Table 1.

Table 1. Residential measures.

\begin{tabular}{|c|c|c|}
\hline Scenario & Measure & $\begin{array}{c}\text { Implementation rate } \\
\text { (by 2050) }\end{array}$ \\
\hline $\begin{array}{l}\text { Behavioral } \\
\text { changes }\end{array}$ & $\begin{array}{l}\text { 1. Regulation of room air temperature } \\
\text { (Heating: STD }-2{ }^{\circ} \mathrm{C} \text {; Cooling: STD } \\
+1{ }^{\circ} \mathrm{C} \text { ) } \\
\text { 2. Regulation of space heating and } \\
\text { cooling operation time (STD } \times 0.75 \text { ) } \\
\text { 3. Reduction of hot water supply } \\
\text { temperature (STD }+{ }^{\circ} \mathrm{C} \text { ) } \\
\text { 4. Reduction of hot water use } \\
\text { 5. Using cold water during summer } \\
\text { 6. Unplugging electrical equipment when } \\
\text { not in use } \\
\text { 7. Only washing clothes when there is a } \\
\text { large load } \\
\text { 8. Washing clothes using shorter cycles } \\
\text { 9. Closing the lid of warm-water } \\
\text { cleaning toilet seats } \\
\text { 10. Adjusting the temperature setting of } \\
\text { warm-water cleaning toilet seats }\end{array}$ & $\begin{array}{l}\text { Implemented by } 50 \% \text { of all } \\
\text { households }\end{array}$ \\
\hline $\begin{array}{l}\text { Equipment } \\
\text { improvement }\end{array}$ & $\begin{array}{l}\text { 1. Old air conditioners replaced by } \\
\text { energy-efficient models } \\
\text { 2. Enhancement of thermal insulation } \\
\text { level } \\
\text { 3. Water heaters replaced by heat pumps } \\
\text { 4. Use of water-saving shower heads } \\
\text { 5. Kerosene water heaters replaced by } \\
\text { heat pump models } \\
\text { 6. Replacement of incandescent bulbs } \\
\text { with compact fluorescent lamps } \\
\text { 7. Accelerating the adoption of eco- } \\
\text { appliances }\end{array}$ & $\begin{array}{l}\text { Increase of COP: Heating } \\
\text { from } 3.0 \text { to } 8.0 \text {; Cooling from } \\
4.0 \text { to } 8.0 \\
\text { All houses meet new standard } \\
\text { Increase of COP: } 3.0 \rightarrow 6.0 \\
\text { Implemented by } 50 \% \text { of all } \\
\text { households } \\
\text { Electrification rate increases } \\
2.5 \% \text { every } 5 \text { years } \\
\text { Implemented by } 50 \% \text { of all } \\
\text { households } \\
\text { Reduction of power } \\
\text { consumption: } 70 \% \text { reduction } \\
\text { of refrigerators, } 75 \% \\
\text { reduction of TVs (compared } \\
\text { to } 2005 \text { ) }\end{array}$ \\
\hline
\end{tabular}

As for electrical measures, the electric utilities made contributions to global warming mitigation. The $\mathrm{CO}_{2}$ intensity of electricity in Shanghai was $1.027 \mathrm{~kg}-\mathrm{CO}_{2} / \mathrm{kWh}$ in 1990 , which we use as the baseline figure (100\%). The NDRC scenario was based on da farom the National Development and Reform Commission (NDRC) of China. According to NDRC, 
the emissions rate will decrease to $80 \%$ of the baseline amount by 2030 . The METI scenario was proposed by the Ministry of Economy, Trade and Industry (METI) of Japan. In the METI scenario, the reduction rate of the $\mathrm{CO}_{2}$ intensity of electricity will be even larger, to $40 \%$ of the baseline amount by 2050 .

\subsection{Commercial Projections}

\subsubsection{Summary of the macro-model}

Figure 2 shows the estimated flow chart of the macro-model applied to the commercial sector. Total energy consumption was divided into two parts: air conditioning and other electrical appliances. Air conditioning includes cooling and heating; other electrical appliances include lighting, computers, and other heating devices. The macro-model is a simulation model that estimates changes in energy consumption according to building type (retail space and hotels, office buildings, warehouses, education facilities, hospitals, and personal services facilities and others) and application (air conditioning, lighting, computing, and others) over a 5-year period.

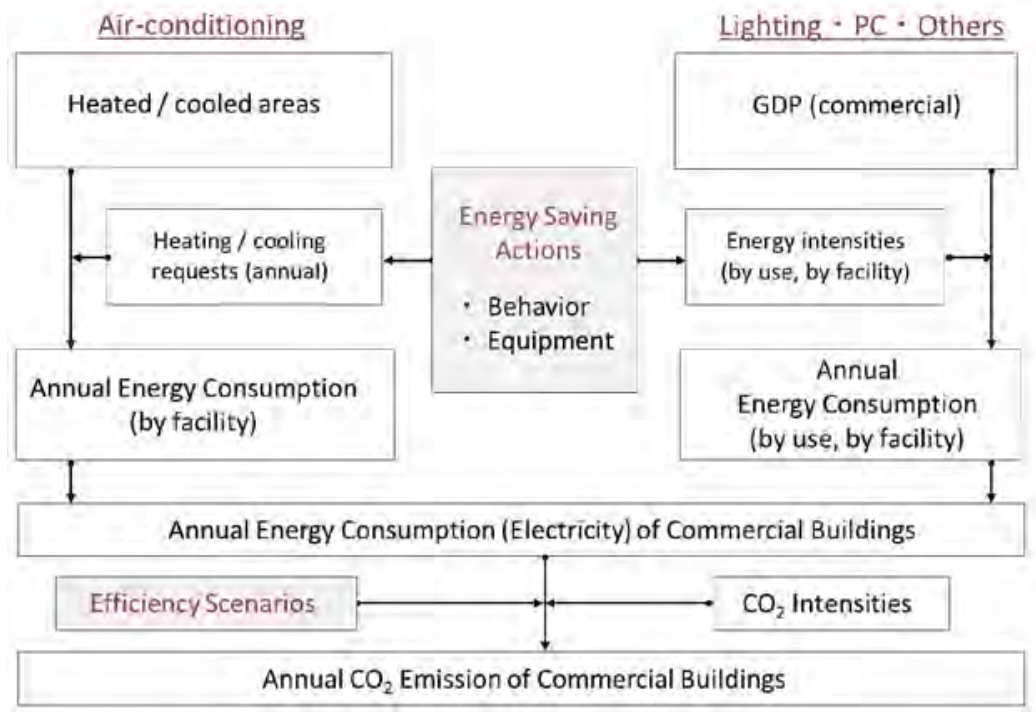

Fig. 2. Flow chart of the commercial sector model.

The commercial model is also a bottom-up engineering model that estimates energy consumption similarly to the residential model. Hence, we analyzed the connection between GDP and penetration rates of electrical appliances in the past 10 years to project penetration rates though 2050 .

\subsubsection{Model parameters}

Because this is prediction research, every parameter was set through 2050 . The data for 2000 and 2005 were primarily from the Shanghai Yearbook. Parameters for future years were based on relevant literature and the author's assumptions.

For the GDP projection, we referred to research results from the Department of Foreign Affairs and Trade (Wu, 1997) that suggested Chinese GDP will continue growing sharply and overtake the GDP of the United States by 2020. We then looked at the historical growth patterns of another Asian country, namely, Japan. Japan has also been through a period of high growth and development, starting with the "Golden Sixties" and ending with the "Lost Decade." After this period, growth became stable and the trend line became flat. China is now 
going through a period of high growth. On the basis of the two perspectives above, we assumed that this unusually high growth in China will last until 2030, at which time it will start slowing down. The GDP of Shanghai's service sector was projected through 2050 using this same trend line, as shown in Fig. 3 (left). Using a similar approach, we also projected the labor force and gross floor space for the next 40 years. For the labor force projection, we referred to the population projection by the Shanghai Municipal Population and Family Planning Commission (SMPC) and calculated labor force as a share of the overall population. For gross floor area, we analyzed the growth pattern over the past 10 years (Xing, 2010) and projected future gross floor area through 2050, as shown in Figure 3 (right).
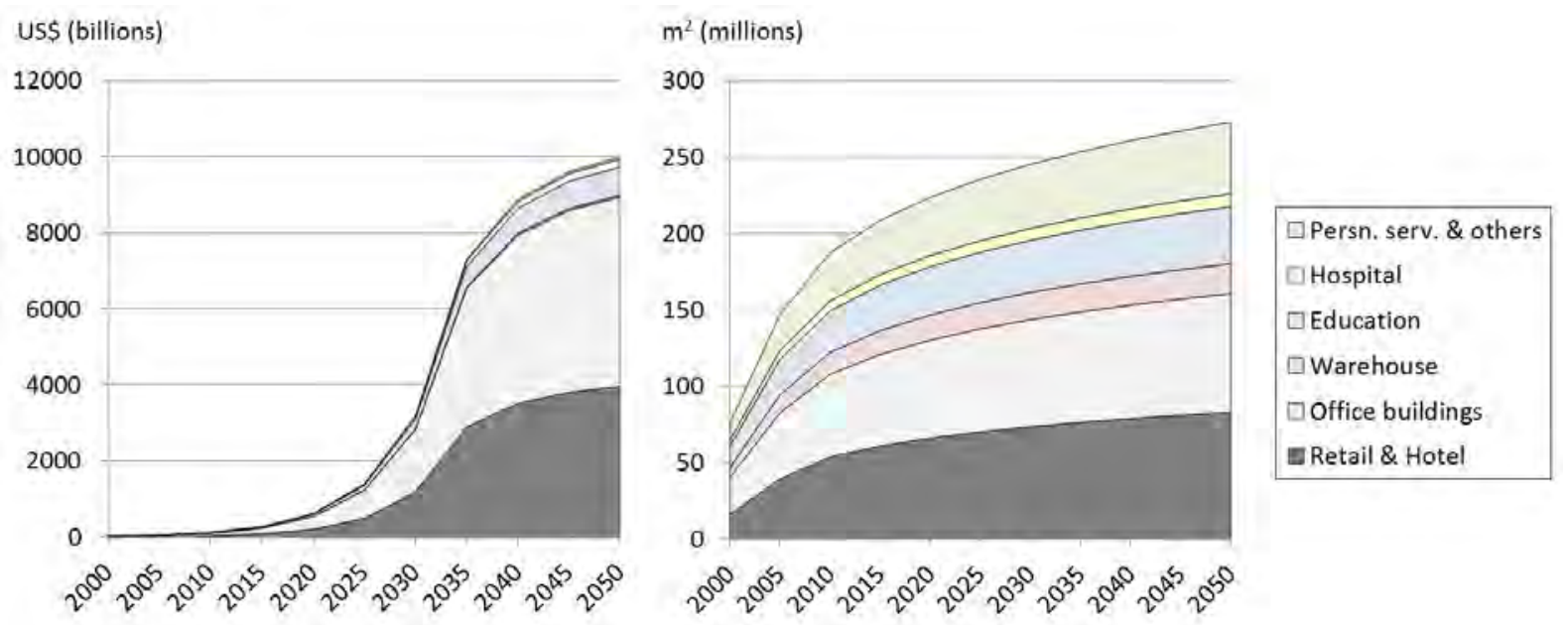

Fig. 3. Projected GDP (left) and floor space (right) through 2050.

Table 2. Commercial measures.

\begin{tabular}{|c|c|c|c|}
\hline \multirow{2}{*}{$\begin{array}{l}\text { Electrical } \\
\text { application }\end{array}$} & \multirow[b]{2}{*}{$\mathrm{BaU}$} & \multicolumn{2}{|c|}{ Energy saving scenarios } \\
\hline & & Behavioral changes & $\begin{array}{c}\text { Equipment } \\
\text { improvement }\end{array}$ \\
\hline $\begin{array}{l}\text { Air } \\
\text { conditioning }\end{array}$ & $\begin{array}{l}\text { Heating } 18^{\circ} \mathrm{C}, \\
\text { cooling } 26^{\circ} \mathrm{C} \\
\text { COP: } 3.54\end{array}$ & $\begin{array}{l}\text { Heating } 17^{\circ} \mathrm{C} \text {, cooling } 27^{\circ} \mathrm{C} \\
\text { Operational time } \times 0.75\end{array}$ & COP: $3.54 \rightarrow 8.0$ \\
\hline Lighting & $\begin{array}{l}\text { Lighting is used } \\
\text { all day }\end{array}$ & Turn off the lights when away & $\begin{array}{l}\text { Adoption of LED } \\
\text { lighting }\end{array}$ \\
\hline Computer & $\begin{array}{l}\text { PC enters sleep } \\
\text { mode after work }\end{array}$ & Shut down PC after work & $\begin{array}{l}\text { Adoption of ECO- } \\
\text { PC }\end{array}$ \\
\hline $\begin{array}{l}\text { Other heating } \\
\text { devices }\end{array}$ & $\begin{array}{l}\text { Waste of standby } \\
\text { power }\end{array}$ & $\begin{array}{l}\text { Unplugging electrical } \\
\text { equipment when not in use }\end{array}$ & None \\
\hline
\end{tabular}

\subsubsection{Scenarios}

Two projection scenarios for the commercial sector were also examined: one for commercial measures and another for electrical measures. As for the residential sector, we recommend behavioral changes and equipment improvements as global warming countermeasures for the commercial sector. Table 3 shows the operating power settings for electrical applications by building type under different energy use scenarios. In the Global Energy Assessment (GEA) electrical scenario, the $\mathrm{CO}_{2}$ intensity of electricity will decrease to $10 \%$ of the baseline amount by 2050 . 
Table 3. Operational power settings by application and building type

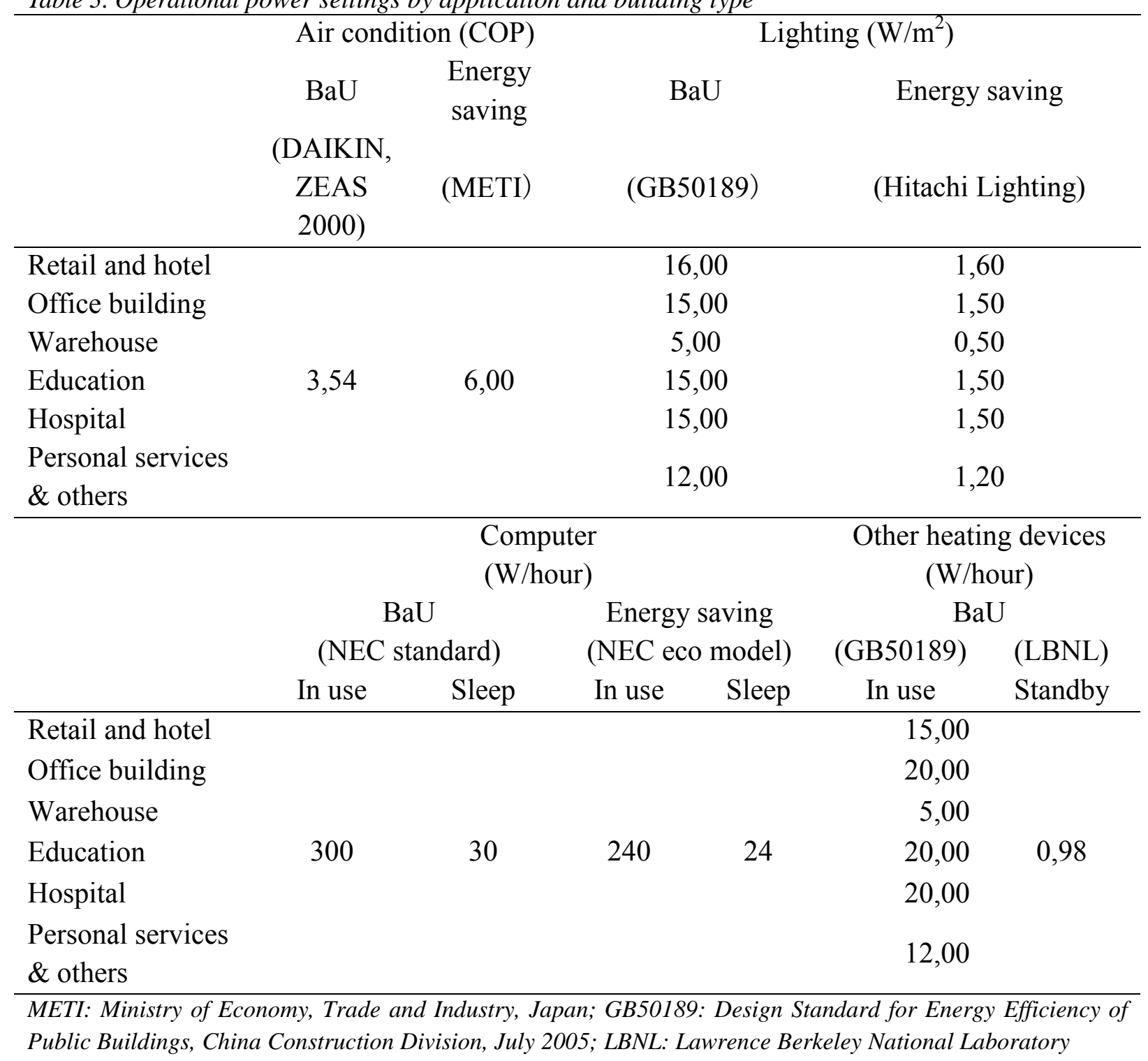

\section{Results}

We first compared the estimation results with government statistics to verify the reliability of the macro-model (Fig. 4). In the years 1990, 2000, and 2005, total annual energy consumption estimated by the macro-model was very close to the government's statistics, suggesting that this model is reliable.
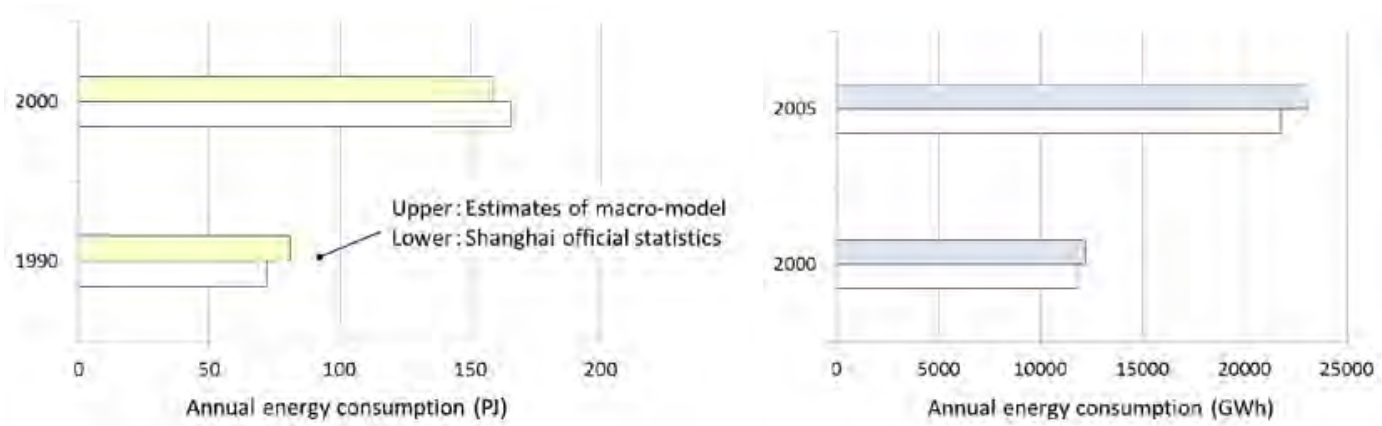

Fig. 4. Macro-model estimates and official statistics for the residential sector (left) and the commercial sector (right). 


\section{1. $\mathrm{CO}_{2}$ Emission Reduction of Residential Buildings}

The BaU scenario showed a 2.7 fold increase in $\mathrm{CO}_{2}$ emissions above the 1990 level by 2050 . Under the scenario where residential measures are adopted, behavioral changes caused a $6 \%$ reduction in $\mathrm{CO}_{2}$ emissions by $2050 \mathrm{c}$ ompared with $\mathrm{BaU}$. Equipment improvements contributed an additional $18 \%$ reduction, which increased the total benefit of residential measures to $24 \%$ below the $\mathrm{BaU}$ scenario for 2050 . When we combined residential measures with the NDRC scenario, the total emissions reductions reached $40 \%$. Residential measures combined with the METI scenario reduced emissions by $65 \%$. Figure 5 (top) shows the projected $\mathrm{CO}_{2}$ emission reductions for the residential sector by electrical application.
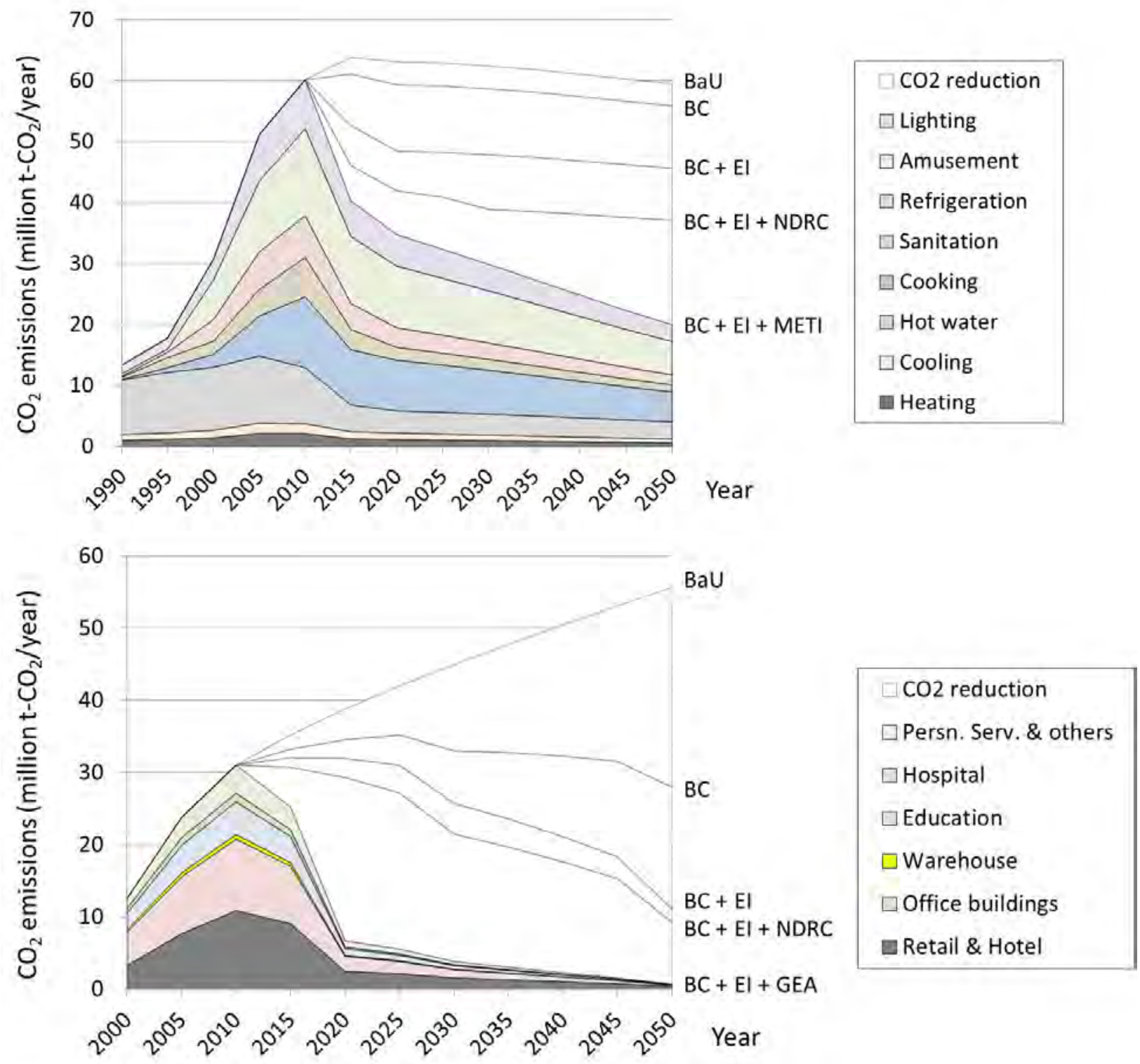

Fig. 5. Projected CO2 emissions for residential buildings (top) and commercial buildings (bottom). BC: Behavioral Changes; EI: Equipment Improvement; NDRC: National Development and Reform Commission of China; METI: Ministry of Economy, Trade and Industry of Japan; GEA: Global Energy Assessment, High case, CPA, WiP 0.5.1 


\section{2. $\mathrm{CO}_{2}$ Emission Reduction of Commercial Buildings}

Similar to the residential sector, the $\mathrm{BaU}$ scenario saw a 3.43 fold increase in $\mathrm{CO}_{2}$ emissions by 2050 for the commercial sector above the 2000 level. The $\mathrm{CO}_{2}$ emission estimates for commercial buildings were projected by building type and electrical application. Figure 5 (bottom) shows the results for commercial buildings by building type.

Under the scenario where commercial measures are implemented, behavioral changes caused a $50 \%$ reduction of $\mathrm{CO}_{2}$ emissions compared with the $\mathrm{BaU}$ scenario by 2050 . Equipment improvements contributed an additional 30\% reduction, which increased the total benefit of residential measures to $80 \%$. When we combined commercial measures with the NDRC scenario, total emissions reductions reached $83 \%$. Commercial measures with the GEA scenario reduced emissions by $99 \%$, which means near-zero contributions of $\mathrm{CO}_{2}$ emissions from commercial buildings.

\section{Discussion and Conclusions}

In this study, we developed a model to predict the $\mathrm{CO}_{2}$ emission reduction potentials by 2050 for diverse climates and policy scenarios. For energy savings in commercial buildings, we found that behavioral changes appear to be more efficient than equipment improvement. This finding will likely be appreciated in a developing country like China, since there is a limited budget for large-scale replacement of equipment.

In general, the projections in this research are theoretical. There is no evidence showing that all the suggested energy saving actions could be fully implemented as described in the scenarios projected. However, we hope the results of this research will help decision makers when they look for solutions to achieve $\mathrm{CO}_{2}$ emission reduction goals in the future.

For the model parameters, we generally relied on the literature and official statistics. In future research, we will schedule local surveys and field measurements in Shanghai. These efforts are expected to improve the accuracy and reliability of the projection model.

\section{Acknowledgment}

This work was supported in part by a Grant-in-Aid for the Global Center of Excellence Program for the "Center for Education and Research of Symbiotic, Safe and Secure System Design" from the Ministry of Education, Culture, Sport, and Technology, Japan.

\section{References}

[1] J. Gaines \& Stefan Jager, A Manifesto for Sustainable Cities, Prestel Publishing, $1^{\text {st }}$ Edition, 2009, pp. 66.

[2] T. Ikaga et al., Development of Macro Simulation Method on H ousehold Energy Consumption and $\mathrm{CO}_{2}$ Emissions by Each Administrative Division: Journal of Technology and Design, Architectural Institute of Japan, 2005, Vol. 22, pp. 264-268.

[3] Hurry X. Wu, Measuring China's GDP, Department of Foreign Affairs and Trade of Australia, Briefing Paper Series No. 8, 1997, pp. 24.

[4] Rui Xing, Effective Energy Efficient Policies for Commercial Building in Shanghai, Young Science Summer Program (IIASA), 2010 